\title{
Investigation of energy management in an Iranian construction project
}

\author{
S. Ajel, M. B. Nobakht \& M. Harischian \\ Azad Islamic University, Iran
}

\begin{abstract}
The subject of constraints and lack of sustainable energy on Earth is now obvious to all. Hence this research is to probe ways to deal with this problem and to improve project management in order to maintain energy and national benefits. Field studies on present research are about a construction project in Iran. This paper analyses the results of the obtained data.
\end{abstract}

Keywords: energy management, energy resources, waste of energy.

\section{Introduction}

Energy management is a process consisting of schematization, organizing, conducting and supervising in order to optimizing energy consumption. It also avoids the reduction of system service levels (SUT [1]).

Structural, mechanical geotechnical, environmental, traffic and architectural groups are mainly involved in different construction projects such as hospitals, roads, factories and dams. Therefore, it is absolutely essential to have an energy expert optimizing the energy consumption rate.

The building sector in Iran uses one third of the total available energy; it equates to approximately 6 billion dollars. Although this is a noticeable amount, most of the buildings do not fulfill the technical requirements of isolations. The lack of energy resources is not deniable; hence this paper is prepared to improve the managerial techniques of energy saving processes (Murco [6]) (Markus [2]).

The rate of energy consumption has increased enormously during recent decades. There are two major reasons for this. One is due to the industrial revolutions in Iran. The other factor originates from the low prices of energy which prevents the logical consumption and efforts to save energy. 
During the 1974 energy crisis, the energy uses procedures changed a lot as a result of high prices on crude oil and energy resources. Furthermore, oildependent countries tried to manage he new energy resources (Gordić [7]). They strongly approved the logical consumption of energy, and therefore, they paid attention on the main energy consuming centers, i.e. residential buildings. As a result optimization methods became standard.

Nowadays, there are many countries, such as Germany, Sweden, Italy and England which have set up strict rules on building isolation materials, heating and cooling instruments and technical specifications.

Applying these simple but necessary steps has resulted in a 30\% energy saving. According to Iranian statistics in the field of energy in 2009, the residential and commercial sectors use about $40 \%$ of the total energy. So, a reachable saving of $30 \%$ in this part is comprehensively noticeable (Figueiredo [8], Rezapour [3]) .

\section{Principles of energy management in buildings}

\subsection{Methods in identifying sources of energy waste in residential buildings}

To identify sources of energy loss in residential and commercial buildings it is necessary to review the overall energy (energy audits). They can be compared to the results of a relatively ideal model of a general sample structure in order to determine sources of energy waste.

Energy review, if done properly, can be used as a guide for those who have the responsibility to control the energy. Points that are critical in providing the necessary model to determine the sources of loss in residential buildings must have considered the foregoing sections: (Bellarmine [9]) (Mahajan [4]).

\subsection{Production of energy consumption state}

The amount of energy consumption in different seasons is varied. Therefore, the monthly average value of the energy will be considered.

Building energy consumption compared with the standard value (standard uses of different carriers), determine the savings which can help in making decisions on energy audits (Hepbasli [10]).

\subsection{Construction overview (Walk Through)}

The energy auditor at this stage must briefly examine the building and shall identify the following: (Hepbasli [10]).

- Determine the equipment needed to measure.

- Determination of various parts of the building energy consumption.

- Set a clear waste of resources.

- Check the status of energy control.

- Check all electrical equipment.

- Review how the air flows in buildings (Infiltration). 
- Determine the composition of technical team (architect, electrical engineer, mechanical engineer).

\subsection{Access to general information of the building (Building Public Profile)}

Access to general information may include items such as the building materials used in the construction and various components of each building and equipment.

For this purpose, the development and increased understanding of material's mechanical, chemical and thermodynamic behavior, properties of light and also familiarity with newly invented materials, analytical models for heating and cooling properties of used materials can be useful (Farag [12]).

To attain the overall condition of the structure, general information covering the building faces (roof, walls, floors and the type), the area, windows and walls, energy system of heating and cooling (HVAC), form and direction of building, climate profile (temperature and humidity), windows size and position (for optimum use of solar energy should take be taken into consideration (Lampret [13]).

\section{Abadgaran tourist town [5]}

\subsection{Project introduction}

The Koohsangi Welfare and Tourist Project is located in about 47 hectares of land in the western highlands of Mashhad, Iran. The blocks of the project are orientated with a northerly direction of approximately 30 degrees.

The building's structure is a steel frame. Walls are made by $20 \mathrm{~cm}$ clay partition blocks. A combined stone and brick facade with average thickness of $10 \mathrm{~cm}$ is also observed. In addition, some sections are cement plaster. The roof is covered by light concrete and the final insulation layer is $4 \mathrm{~mm}$ thick.

The finishing indoor layer thickness of gypsum plaster is $2.5 \mathrm{~cm}$ and the final layer of finish on non-health areas, health areas and ceiling are plastic paint, oil based paint and tiles, respectively.

The ceiling is a kind of joist block with light concrete, the floors and the halls are covered by ceramics. In private spaces like bedrooms, the finish is of mosaic with a $2 \mathrm{~cm}$ thickness. The aluminum windows are designed with $4 \mathrm{~mm}$ thick glass. Windows are insulated by cement mortar or plaster. The buildings are also equipped with elevators. Indoor equipment for heating in each unit is prepared separately in each unit. Transfer of heat into the room is through seamless black iron pipes with welded joints. The distribution system to heat spaces is aluminum radiators.

For cooling of buildings, water coolers are located in each unit separately on their balconies. Cold energy transfer to the indoor space is through the channel of galvanized sheets, which is based on a false ceiling. 
Buildings have separate underground parking which is attached to the minor street by a ramp. A water storage tank with capacity of 7000 liters is anticipated on the roof of the building.

Energy source used in the project in the implementation phase of the project was a temporary electrical power split across the city and in some cases extracted from diesel electric power generators.

\subsection{Studies on energy management in projects}

Investigating thorough the project documents concludes that instead of utilizing a central heating center, a unique heating package is assigned for each apartment. It is designed to lower the total energy consumption and avoid the significant amount of energy loss.

According to the table of energy regions in the Iranian building regulations, Mashhad is considered in the category of mean energy needs. Therefore, the project, with 140,000 square meters, was selected as a very suitable model of a residential project for considering the energy management.

Table 1: $\quad$ Energy dissipation through surfaces in hospital.

\begin{tabular}{|c|c|c|c|c|}
\hline $\begin{array}{c}\text { Percentage } \\
\%\end{array}$ & $\begin{array}{c}\text { Annual Energy } \\
\text { Dissipation } \\
\text { Kwh/yr }\end{array}$ & $\begin{array}{c}\text { Degree- } \\
\text { Day }\end{array}$ & $\begin{array}{c}\text { Energy } \\
\text { Dissipation } \\
\text { W/C }\end{array}$ & Type \\
\hline 33.6 & 13627802 & 2509 & 5432 & Ceiling \\
\hline 37.9 & 15388979 & 2509 & 6134 & $\begin{array}{c}\text { External } \\
\text { Walls }\end{array}$ \\
\hline 13.2 & 5373850 & 2509 & 2142 & Windows \\
\hline 0.5 & 852992 & 2509 & 340 & Floor \\
\hline 0.5 & 213248 & 2509 & 85 & $\begin{array}{c}\text { Staircase } \\
\text { Walls }\end{array}$ \\
\hline 12.7 & 5143040 & 2509 & 2050 & Air Change \\
\hline 100 & 40599910 & & 16183 & Total \\
\hline
\end{tabular}

The next step is the plan and the initial distribution of the land area. Constraints of urban planning in cities prevent designers from determining what levels of productivity and space they need. Also, it restricts the energy management considerations. For example, in the project, if the municipal building regulations would have allowed, it was possible that the project was evaluated in terms of energy consumption in both construction phase and operation phase.

In general, it can be said that all levels of the outside environment are reduced in terms of energy and so it is managed much more favorably than was considered before.

The phase of positioning the buildings to the north angle is very important in terms of energy consumption. The current buildings are at an angle of 30 degrees with the north. Windows of these buildings in the hot season are exposed to 
sunlight, which is not satisfactory. If the rotation of the building was to the south, it could have saved energy consumption very much.

Other items that could be examined in the project are type of building structural material which can be very effective in energy consumption. For example, the energy levels used in buildings with steel structure is different to the energy levels used in reinforced concrete structures. This could be extracted by the management team and be reported and presented to the management unit.

Brick partitions used as separator materials can be compared with plaster panels in terms of energy management. Bricks made from clay baked at high temperature are far higher energy users than gypsum, which as a molding material only needs the temperature high enough to remove surplus water from the gypsum. Finally, the energy used in manufacturing these parts is not renewable energy and also has negative points for environment and climate.

In this project, in order to provide insulation in the external faces, clay bricks with $20 \mathrm{~cm}$ thickness have been adopted. We can now use lower thickness but with lower transfer coefficient to solve this problem. For example the use of polyurethane foam, glass wool, foam or concrete foam and plaster.

Decision-making is within the responsibility of the project manager with having the necessary technical reports and several variants. Selection of each item can also provide technical or economic reasons to be discussed.

Many other technical aids can be utilized that could have made optimal use of energy. Among these we can mention the two layers glass in order to maintain the desired temperature in buildings with lower energy consumption.

Another case to be discussed is the possible use of solar energy for preheating cold water to produce hot water, heating systems and bathing water requirements. However, during the project due to the absence of energy management and use of typical methods, it has been neglected.

Not using suitable doors in parking's corridors and stairs is the other issues that could be favorable in energy consumption to keep the temperature of the units to an effective level. With doors separating filter spaces, a boundary between the exterior space and temperature inside the units is produced which is very effective in reducing energy consumption.

Moreover, using polyurethane insulation around hot water pipes in the building could reduce energy consumption and help make savings.

\section{Results of the case study}

In this section, the results from analysis of the gathered data are illustrated. Since Abadgaran has many different types of building, useful information by the sort of building type is presented.

\subsection{Electrical consumption level}

The diagrams in figure 1 show the percentage of the electrical energy consumption for different buildings. The biggest portion is consumed for cooling 

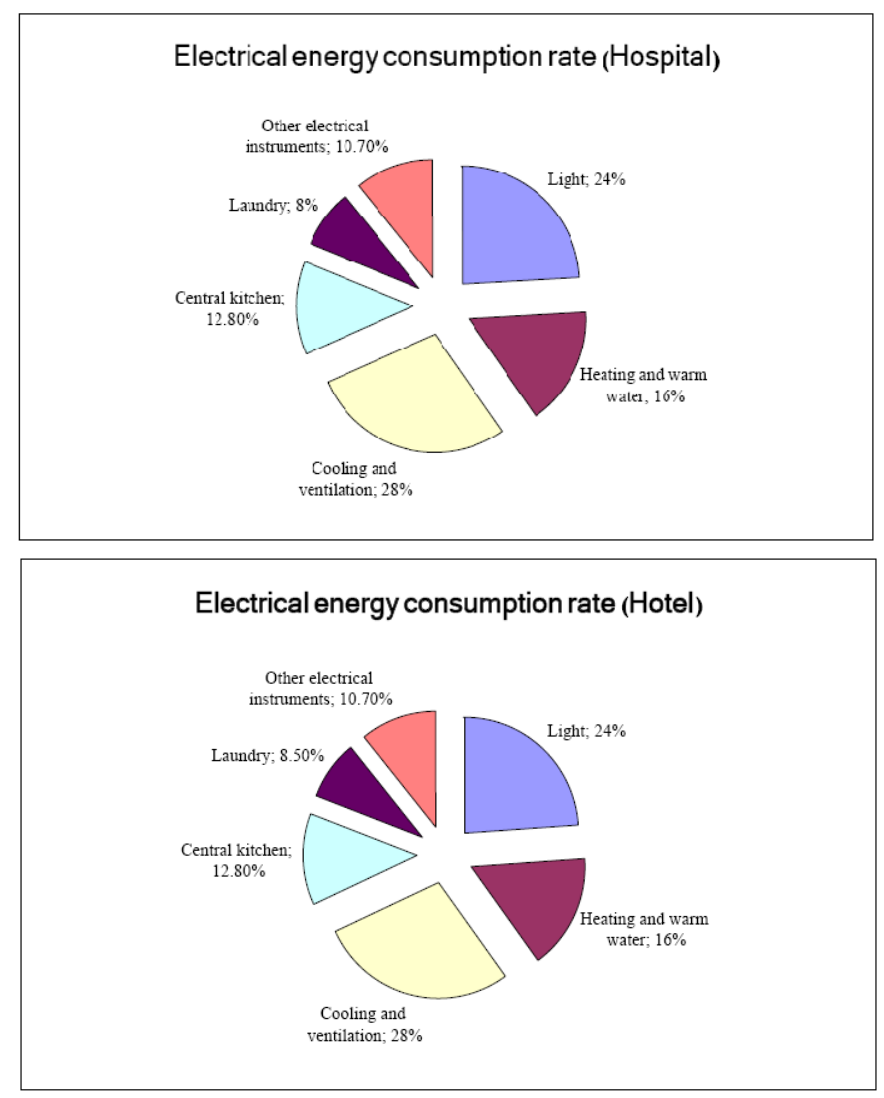

\section{Electrical energy consumption rate (Office building)}

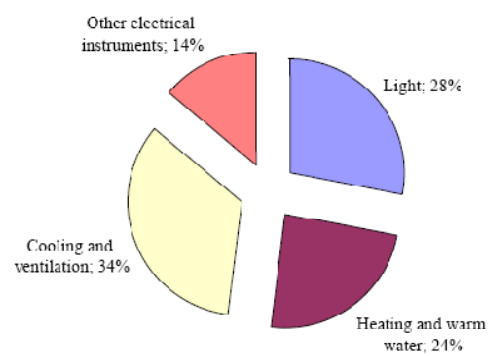

Figure 1: Electrical energy consumption rate.

and ventilation with $28 \%$. Therefore, applying modern equipment with high efficiency has a significant role for energy management. 
It is obvious from the figures that the amount of energy consumes for cooling is about two times more than the electricity for heating. It should be mentioned that this is due to the mechanism of house heating in Iran. As a result of cheaper gas rather than electricity, people prefer to have gaseous heaters.

Also light, with $25 \%$ of the total, is a noteworthy proportion. Various models of new lamps with less energy dissipation can be applied instead. There are also time-control or kinds of intelligent lamps which significantly lower the consumption rate.

\subsection{Electrical and heat energy consumption indices $\left(M J / \mathrm{m}^{2}, \mathrm{KWh} / \mathrm{m}^{2}\right)$}

The indices shown in the diagrams below present the amount of energy consumption over a unit area. In this way in can be applied as adequate indices for comparing the buildings of different types. It is also capable of being compared by the standard norms or the international ones. These indices are illustrated in the diagrams of figure 2 .

In electrical energy consumption indices we can observe that this increases with the amount of floors in residential buildings. For a 12 story building it is three times more than the four story one. Yet, this is not the case for heat energy consumption indices. These are almost the same for buildings with different stories.

At both diagrams, the hospital is the main energy consumer for the electrical and the heat energy consumption indices. It is about three times more than the other building types in heat energy section.

Finally, as is shown, hotels consume the least amount of energy in comparison with the other building types. This is the results of the optimum operation of their equipment; they are all new and have a low energy consumption rate.

\subsection{Heat energy dissipation level through the building external faces}

Considering the air change rate and penetration losses the graphs in figure 3 are plotted. They show the building heating load (required heat energy) and the heat transfer coefficient of the building external surfaces. The heat energy dissipation is calculated by the Degree-Day method.

The percentage of energy dissipation through building surfaces such as ceilings, floors, external walls and the windows are presented in this diagram. Consequently, isolation processes using the double window are recommended to lower the energy consumption.

\subsection{Electrical and heat energy saving potentials}

Saving potentials can be attained by applying the common methods of energy consumption optimizing. The savings are calculated through isolating the external surfaces (ceiling, floor and external walls), double windows, central thermostatic controlling, energy saving bulbs and other proposed procedures. 

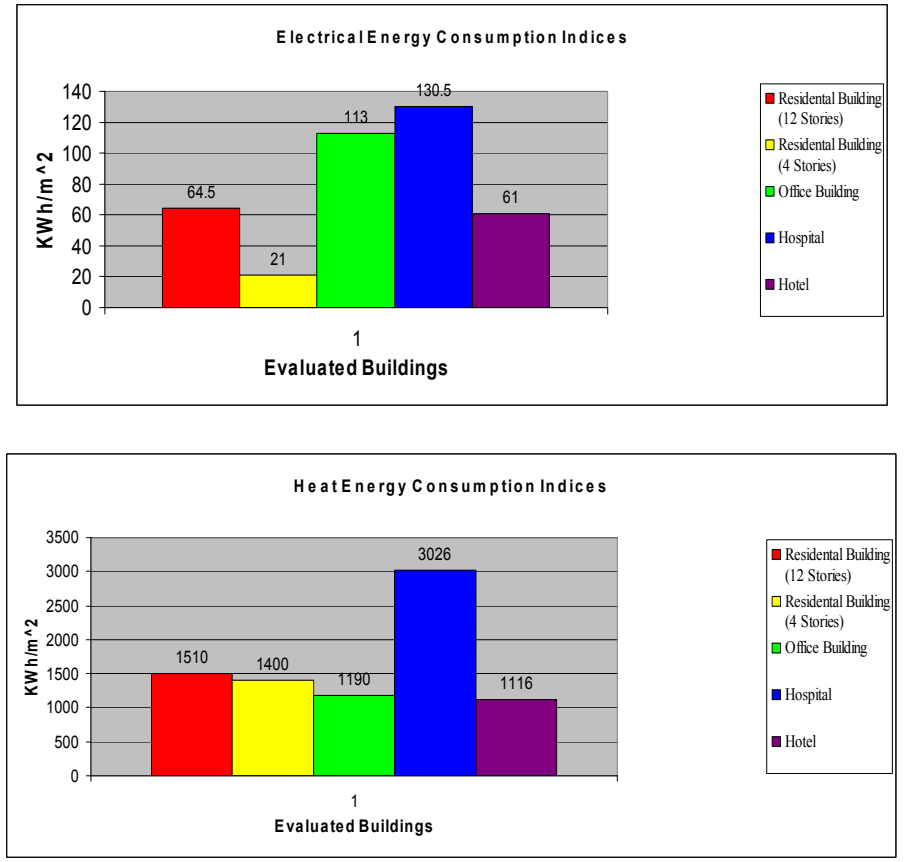

Figure 2: The electrical and heat energy consumption indices in the evaluated buildings.

\section{Energy Dissipation Level in Hospital}

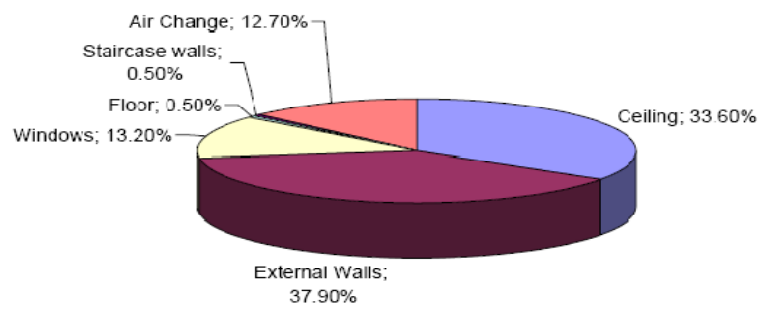

Figure 3: Energy dissipation level in hospital. 

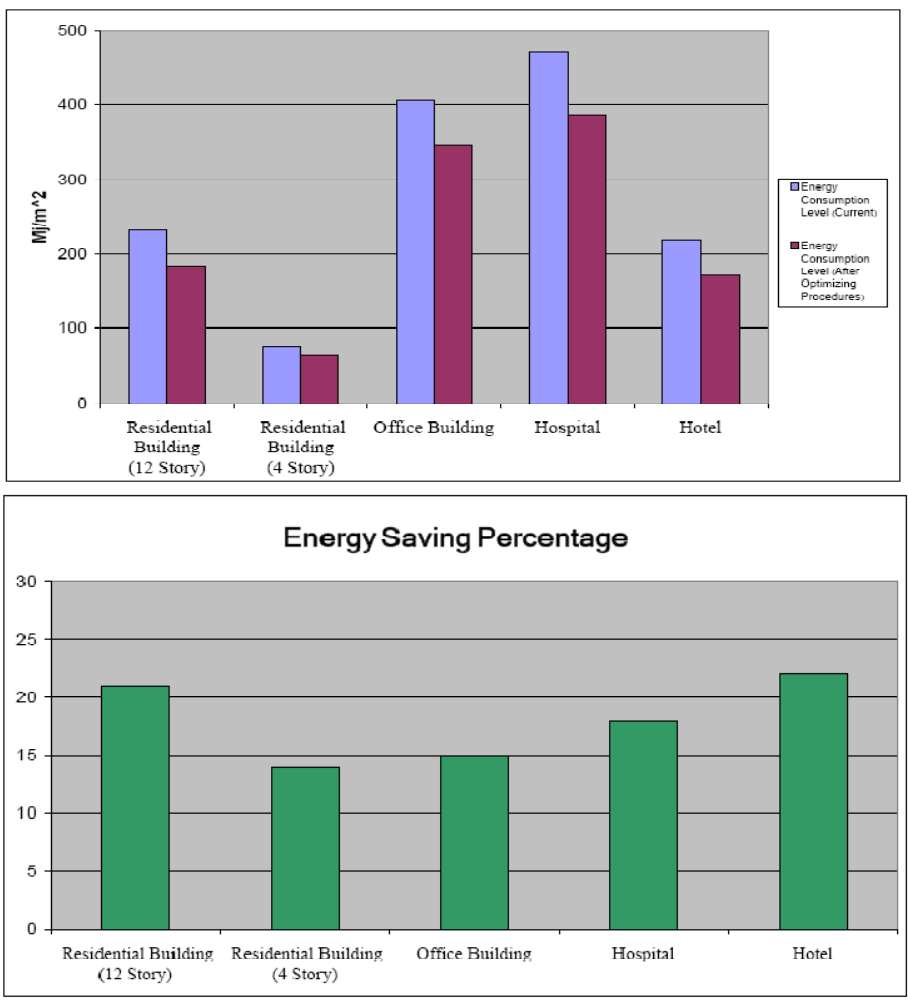

Figure 4: Electrical saving potentials and the consumption rate after optimizing procedures.

Table 2: Electrical saving potentials and the consumption rate after the optimizing procedures.

\begin{tabular}{|c|c|c|c|c|c|}
\hline $\begin{array}{c}\text { Annual } \\
\text { Energy } \\
\begin{array}{c}\text { Saving } \\
\text { (tones of } \\
\text { crude oil) }\end{array}\end{array}$ & $\begin{array}{c}\text { Saving } \\
\text { Energy }\end{array}$ & $\begin{array}{c}\text { Energy } \\
\text { consumption } \\
\text { Indices } \\
\text { (after } \\
\text { optimizing) }\end{array}$ & $\begin{array}{c}\text { Energy } \\
\text { consumption } \\
\text { Indices (current) }\end{array}$ & Area & \multirow{2}{*}{$\begin{array}{c}\text { Building } \\
\text { Type }\end{array}$} \\
\hline TOE & $\%$ & $\begin{array}{c}\text { Return period } \\
3-5 \text { years }\end{array}$ & 5 & 50400 & $\begin{array}{c}\text { Residential } \\
\text { Building } \\
\text { (12 Stories) }\end{array}$ \\
\hline 174.96 & 21 & 51 & 64.5 & 1578 & $\begin{array}{c}\text { Residential } \\
\text { Building } \\
\text { (4 Stories) }\end{array}$ \\
\hline 1 & 14 & 18 & 21 & 9230 & $\begin{array}{c}\text { Office } \\
\text { Building }\end{array}$ \\
\hline 40 & 15 & 96 & 113 & 38601 & Hospital \\
\hline 233 & 18 & 107 & 130.5 & 3781 & Hotel \\
\hline 13 & 22 & 47.6 & 61 & &
\end{tabular}


As observed, the external walls and the ceiling have the biggest role in energy dissipation. They cause about two third of the whole energy loss. So, it is very important to take care about the isolation procedures in exposed surfaces.

The table illustrates the percentage of the energy saving for different building types by considering the energy management and avoiding the energy dissipation as much as possible. Using all the applicable procedures, the residential building with 12 stories and the hotel have achieved about $20 \%$ saving in total energy which is very significant. At the least amount we can observe the $14 \%$ of the residential building with four stories. It should be reminded that this case had suitable initial energy consumption according to figure 2.

\section{Conclusions}

It should be emphasized that economic justification and investment limitations are the main factors in any program for optimizing the energy consumption. Therefore, all the renewable energy resources should be investigated at first, and then the potential for different energy at the site must be determined. Briefly, replacing the new energy needs decision making, thinking, organizing and finally investment.

It is also necessary that the international organizations support the new energy methods programs financially. Modern technologies play an important role in optimizing programs as well.

The prices for different types of energy are frequently fluctuating because of the changes in the operational techniques and devices. Gathering the required data, the responsible managers can opt for optimized solutions and different energy resources in their construction projects.

Solar, wind and geothermal energy can be used singularly or in combination with each other. It has been proved that the subsidies on fossil fuels are a major obstacle against the development of the renewable energy resources. Currently in Iran, the government is seriously omitting these subsidies and has gained enough success to continue this national project.

According to the results at least $14 \%$ energy saving can be achieved by taking care of the external walls and the ceilings. It should be reminded that two third of energy dissipation is from these faces, so it is important to pay attention to these.

\section{References}

[1] Sharif University of Technology, applicable reference for energy management, oil and energy department, Persian language. (2007),

[2] D.Markus, Translated by H.Shirazi, energy management of buildings, Zare publications, Iran, Persian language, 2004.

[3] K.Rezapour, Saves principles of energy management, SAYA Organization, Iran , 2007

[4] K.Mahajan, Energy management, efficient uses of energy, Basir Publications, Iran, Persian language, 2005

[5] Abadgaran Construction Company, www.oonegroup.com 
[6] Mashhad Subway Organization, www.murco.ir

[7] Dušan Gordić, Development of energy management system - Case study of Serbian car manufacturer. Energy Conversion and Management. 51(12). , 2010.

[8] João Figueiredo, Energy Production System Management - Renewable energy power supply integration with Building Automation System. Energy Conversion and Management. 51(6), pp 1120-1126, 2010

[9] G. Thomas Bellarmine, Energy conservation and management in the U.S. Energy Conversion and Management. 35(4), pp 363-373, 1994.

[10] Arif Hepbasli, Development of energy efficiency and management implementation in the Turkish industrial sector. Energy Conversion and Management 44(2), pp 231-249, 2003.

[11] Benjamin Paris. Heating control schemes for energy management in buildings. Energy and Buildings. 42(10), pp 1908-1917, 2010.

[12] S. Farag. March 1999, Cost effective utilities energy plans optimization and management. Energy Conversion and Management. 40(5), pp 527-543

[13] Marko Lampret., Industrial energy-flow management. Applied Energy. 84(7), pp 781-794. 2007. 